\title{
Feasibility of Hybrid Energy Aware Routing for Ad-hoc Network
}

\author{
Gaurav Vishnu Londhe, Dilendra Hiren
}

\begin{abstract}
In today's modern era we are facing difficulties in data connectivity, the speed to which the data is transferred and drop in network causes delay in data transfer are the few vulnerabilities we found in the recent years researches in the area of wireless sensor networks. As we have referred in literature to overcome such drawbacks of the existing systems the proposed methodology is planned to recover the issue even in the congestion scenario to avoid the drop in the network and provide the efficient data connectivity with the results of the suggested approach help us to conclude about it with simulation results.
\end{abstract}

Keywords, Hybrid, Ad-Hoc Network, Energy Aware

\section{INTRODUCTION}

This paper is emphasizing on the critical approach of analysis with proposed algorithm with several parameters. This helps us to deduce that, the proposed approach is considered to be beneficial in many aspects for transmission of the message over the Ad hoc Network. Here we are simulating the algorithm and the results are declared which are helpful to understand the result with various parameters in the tabular information. This will help to reduce the time required to transfer the data from source to destination in the given interval of time. Which reduces the frequent network establishment time required due to frequent failure occurred in the earlier method. Therefore, we can share the data in a single transaction only with minimum time duration and maximum throughput.

\section{RELATED WORK}

The template is used to format your paper and style the text. All margins, column widths, line spaces, and text fonts are prescribed; please do not alter them. You may note peculiarities. For example, the head margin in this template measures proportionately more than is customary. This measurement and others are deliberate, using specifications that anticipate your paper as one part of the entire proceedings, and not as an independent document. Please do not revise any of the current designations.

Revised Manuscript Received on February 05, 2020.

* Correspondence Author

Gaurav Vishnu Londhe*, Research Scholar of Department of Computer Science and Engineering, Pacific Academy of Higher Education and Research University, Udaipur, Rajasthan, India. E-mail: gauravlondhe@gmail.com

Dr. Dilendra Hiren, Department of Computer Science and Engineering, Pacific Academy of Higher Education and Research University, Udaipur, Rajasthan, India.

E-mail: sigmapawan72@gmail.com

(C) The Authors. Published by Blue Eyes Intelligence Engineering and Sciences Publication (BEIESP). This is an open access article under the CC BY-NC-ND license (http://creativecommons.org/licenses/by-nc$\underline{\mathrm{nd} / 4.0 /)}$
As per the Dr. Dilendra Hiren and Gaurav Londhe, in the paper energy aware concept need to be considered for hybridization with earlier distance based routing process, which can be further synchronized and scrutinized here in the proposed methodology with experimental base. [1].

1. As per the Indrajeet Banerjee, Suriti Chakrabarty, Arunava Bhattacharya, Utsav Ganguly a method to movet he base station from the neighbourhood of the hotspot locality has been suggested. This algorithm is efficiently able to select the nodes with minimum cost for the given link to route and ensures the nodes with maximum energy have got selected for the given link. This is achieved through cost updating process.

2. As per the Magnus Eriksson and Arif Mahmud, the multiple nodes sending one signal at a time over the one frequency channel. Diverse routing algorithms are suggested and evaluated for the broadcasting scenario with their results of simulations, which shows best algorithm reduces energy consumptions by up to $42 \%$ compared with an existing distance based routing.

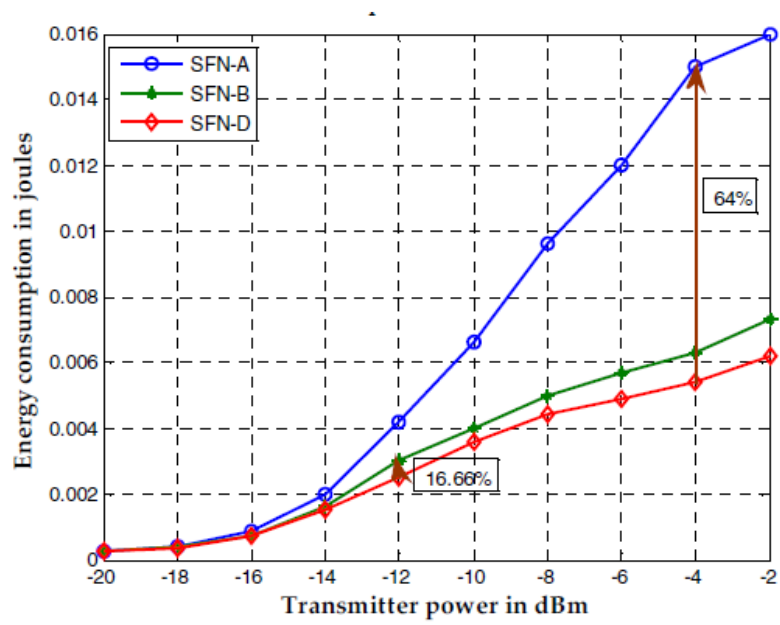

Figure 1. Energy consumption Vs Transmitter power

Here the consumption of energy is described Vs Power of a transmitter in $\mathrm{db}$ is tested and found. Which is $64 \%$ and it significantly high in number to be considered for the calculating the overall through put of the system for passing the message on a wireless network. 
Feasibility of Hybrid Energy Aware Routing for Ad-hoc Network

\section{TABLE I}

COMPARISON OF THE FLOCKING ALGORITHMS ON LARGE TEST NETWORKS The average of percent user connectivity in 30 replications

\begin{tabular}{|c|c|c|c|c|}
\hline $\begin{array}{c}\text { Test } \\
\text { Network } \\
\text { (|Ut|,At|) }\end{array}$ & Random & $\begin{array}{c}\text { Static } \\
\text { Flocking } \\
\text { Setting-(i) }\end{array}$ & $\begin{array}{c}\text { Static } \\
\text { Flocking } \\
\text { Setting-(ii) }\end{array}$ & $\begin{array}{l}\text { Dynamic } \\
\text { Flocking }\end{array}$ \\
\hline$(30,4)$ & 36.09 & 41.64 & 42.04 & 43.9 \\
\hline$(30,5)$ & 39.32 & 44.2 & 44.38 & 47.68 \\
\hline$(30,6)$ & 40.41 & 46.3 & 47.12 & 50.55 \\
\hline$(30,7)$ & 41.12 & 45.88 & 49.76 & 53.75 \\
\hline$(40,4)$ & 55.76 & 56.89 & 58.56 & 62.72 \\
\hline$(40,5)$ & 57.54 & 58.94 & 61.15 & 66.13 \\
\hline$(40,6)$ & 60.24 & 60.39 & 63.22 & 69.34 \\
\hline$(40,7)$ & 62.07 & 62.23 & 65.76 & 72.32 \\
\hline
\end{tabular}

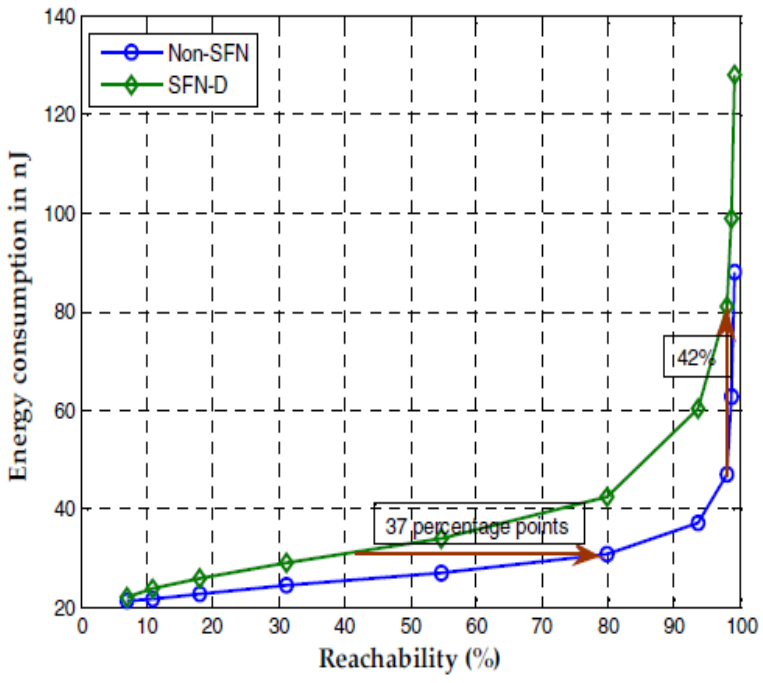

Figure 2 Energy Consumption Vs Reachability [3]

3. As per the Abdullah Konak a new flocking algorithm for the improvement in the connectivity in MANETs through autonomous auxillary nodes which are termed as agents. This updates the distances based on the crowdedness in the vicinity to show the performance in the congestion scenario based on the fixed parameters.

\section{TABLE II}

\begin{tabular}{|c|c|c|c|c|}
\hline \multicolumn{5}{|c|}{$\begin{array}{c}\text { COMPARISON OF THE FLOCKING ALGORITHMS ON SMALL } \\
\text { TEST NETWORKS The average of percent user connectivity in } 30 \\
\text { replications }\end{array}$} \\
\hline $\begin{array}{l}\text { Test } \\
\text { Network } \\
(|\mathrm{Ut}|,|\mathrm{At}|)\end{array}$ & Random & $\begin{array}{l}\text { Mathemat } \\
\text { ical } \\
\text { Programm } \\
\quad \text { ing }\end{array}$ & $\begin{array}{l}\text { Static } \\
\text { Flocking }\end{array}$ & $\begin{array}{l}\text { Dynamic } \\
\text { Flocking }\end{array}$ \\
\hline$(10,2)$ & 14.76 & 18.80 & 18.21 & 17.68 \\
\hline$(10,3)$ & 16.39 & 20.30 & 21.12 & 19.85 \\
\hline$(10,4)$ & 17.69 & 22.36 & 22.25 & 21.84 \\
\hline$(10,5)$ & 17.48 & 24.55 & 23.18 & 23.49 \\
\hline$(10,6)$ & 18.54 & 24.30 & 24.48 & 25.63 \\
\hline$(20,2)$ & 22.33 & 25.51 & 23.61 & 24.84 \\
\hline
\end{tabular}

\begin{tabular}{|l|l|l|l|l|}
\hline$(20,3)$ & 24.09 & 26.92 & 26.19 & 27.47 \\
\hline$(20,4)$ & 24.89 & 27.92 & 28.55 & 30.08 \\
\hline$(20,5)$ & 26.59 & 29.01 & 29.65 & 32.69 \\
\hline
\end{tabular}

4. As suggested by Priyanka R. More and Dr Sankpal in her paper we could observe the overall performance of RMER algorithm with several parameters. RMER is an Energy efficient routing algorithm.

They have obtained simulation results for the PDR, average Energy Delay, throughput, normalized overhead, control overhead. This minimizes the consumption of an energy per packet traversal. Here it does not consider the residual battery energy of the nodes.

\begin{tabular}{|c|c|}
\hline Parameter & Value \\
\hline $\begin{array}{l}\text { Initial battery energy of each node } \\
\text { (B) }\end{array}$ & $100[\mathrm{~J}]$ \\
\hline Network area & $350 * 350[\mathrm{~m} 2]$ \\
\hline Path-loss exponent ( $\mathrm{n})$ & 3 \\
\hline Data rate (r) & $100[\mathrm{Kbps}]$ \\
\hline $\begin{array}{l}\text { Power consumption of transmitter } \\
\text { circuit }\left(\mathrm{P}_{\mathrm{t}}\right)\end{array}$ & $100[\mathrm{~mW}]$ \\
\hline $\begin{array}{l}\text { Power consumption of receiver } \\
\text { circuit }\left(\mathrm{P}_{\mathrm{r}}\right)\end{array}$ & $100[\mathrm{~mW}]$ \\
\hline $\begin{array}{l}\text { Maximum transmission power } \\
\left(\mathrm{P}_{\max }\right)\end{array}$ & $150[\mathrm{~mW}]$ \\
\hline $\begin{array}{l}\text { Minimum transmission power } \\
\left(\mathrm{P}_{\min }\right)\end{array}$ & $15[\mathrm{~mW}]$ \\
\hline $\begin{array}{l}\text { Maximum\# of transmissions in } \\
\text { HBH system( }\left(Q_{u}\right)\end{array}$ & 7 \\
\hline Transmission range $\left(\mathrm{d}_{\max }\right)$ & $70[\mathrm{~m}]$ \\
\hline Data packet size $(\mathrm{Ld}) 512$ [byte] & 512 [byte] \\
\hline MAC ACK packet size $(\mathrm{Lh})$ & 240 [bit] \\
\hline E2E ACK packet size $\left(\mathrm{L}_{\mathrm{e}}\right)$ & 96 [byte] \\
\hline Hello packet size (Lhello) & 96 [byte] \\
\hline Battery death threshold (Bth) & 0 \\
\hline $\begin{array}{l}\text { Maximum collision probability } \\
\text { (Pcmax }\end{array}$ & 0.3 \\
\hline channel sensing time $\left(\mathrm{T}_{\text {sense }}\right)$ & $50[\mu \mathrm{s}]$ \\
\hline Kidle & 0.2 \\
\hline Ksense & 0.4 \\
\hline Thello & $10[\mathrm{~s}]$ \\
\hline $\mathrm{T}_{\mathrm{tc}}$ & $20[\mathrm{~s}]$ \\
\hline
\end{tabular}

Figure 3 Parameters considered for the Network Simulation
Published By:

Blue Eyes Intelligence Engineering \& Sciences Publication 

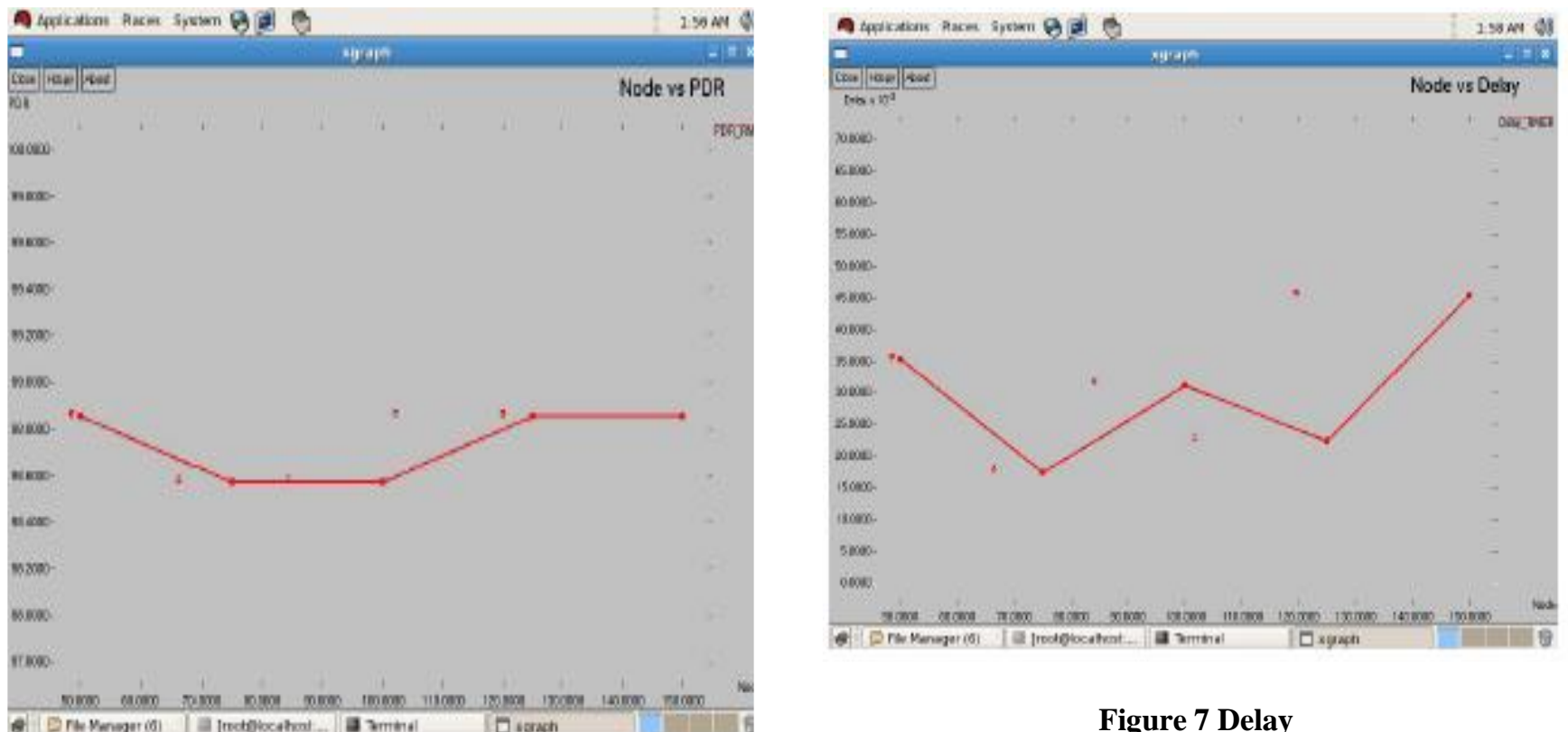

\section{Figure 4 Ratio of Packet delivery}
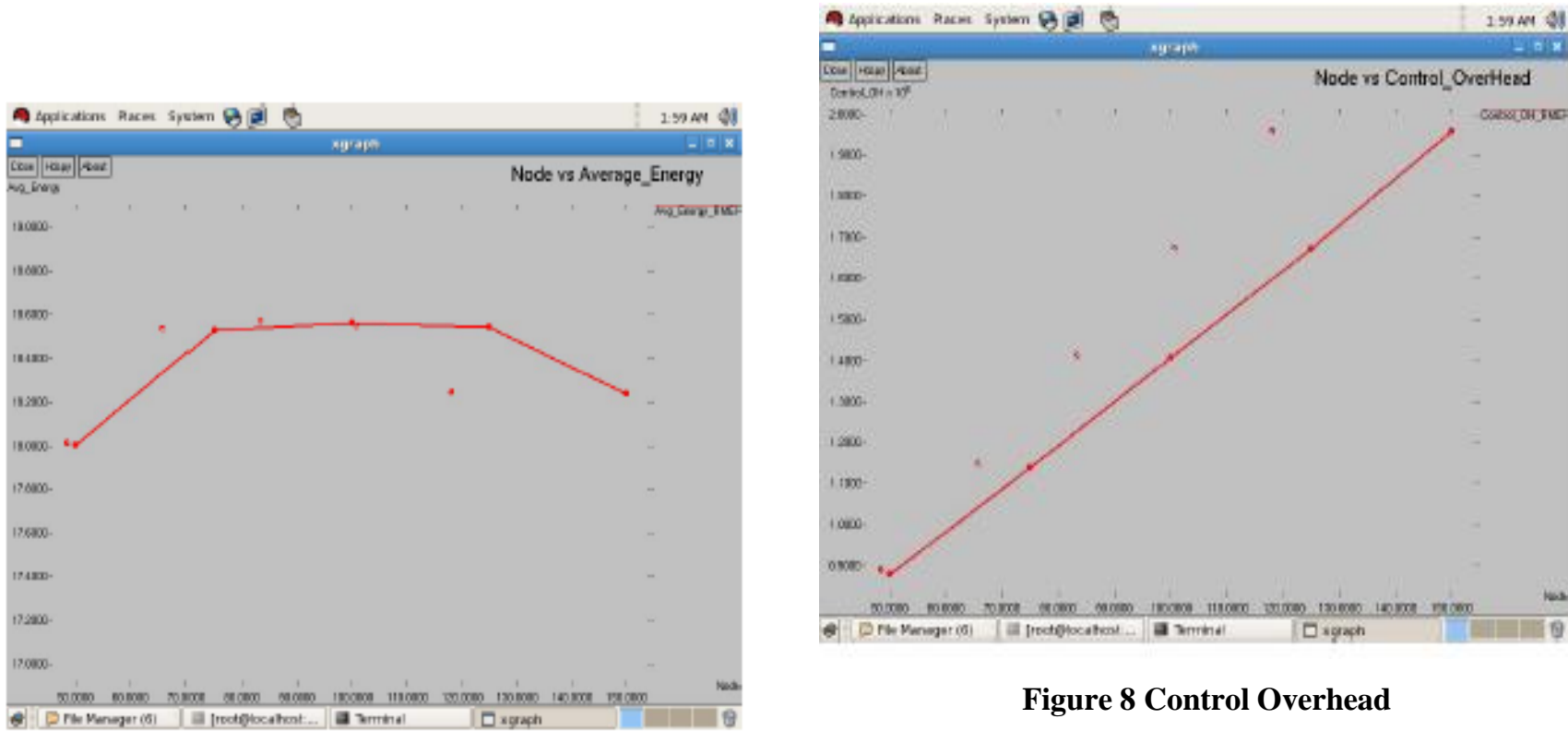

Figure 8 Control Overhead

Figure 5 Average Residual Energy
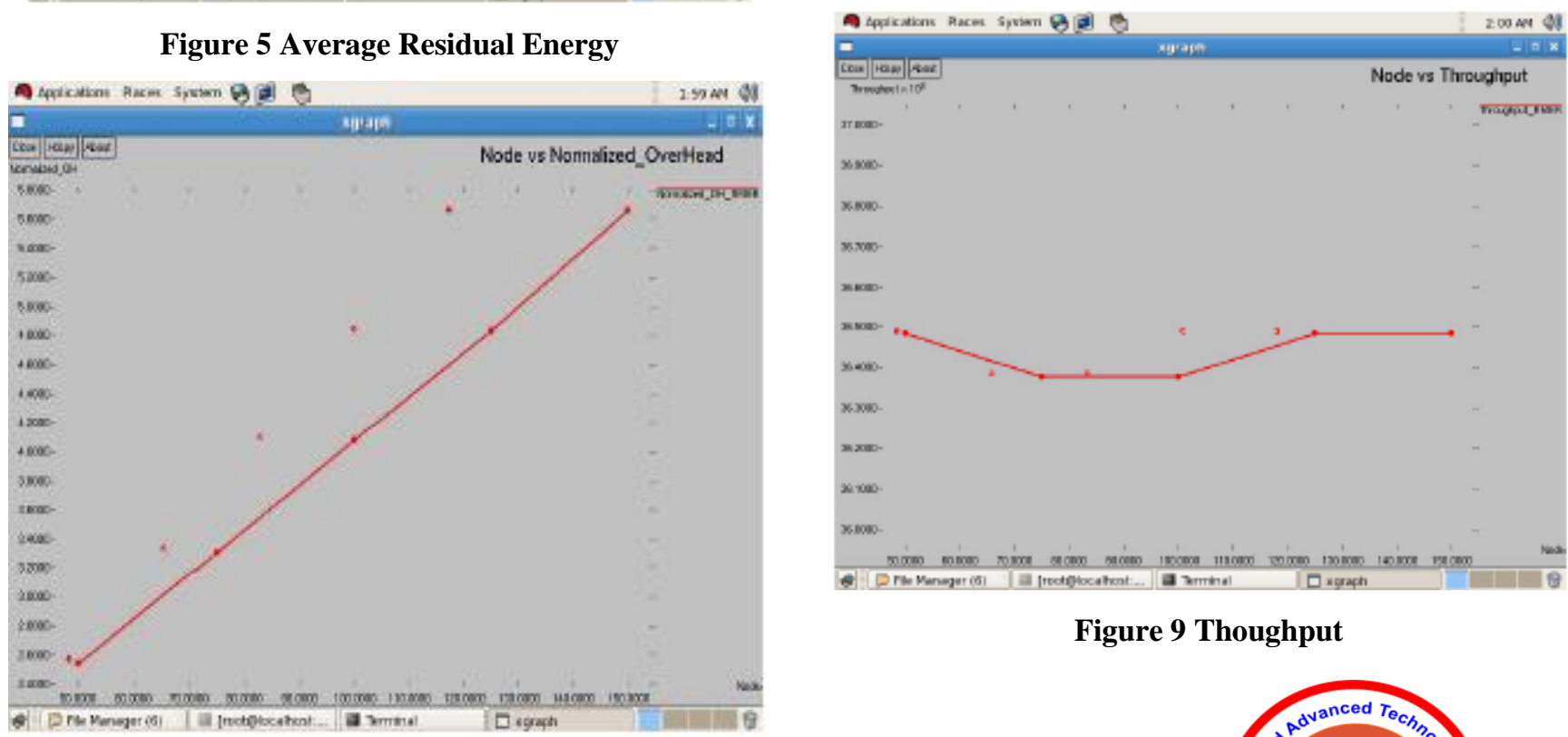

Figure 9 Thoughput

Figure 6 Normalized Overhead

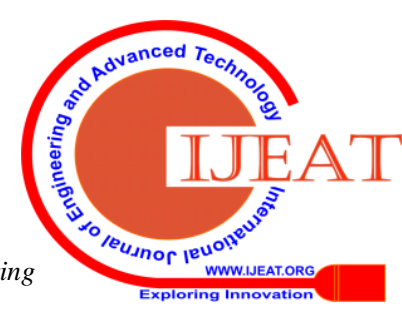




\section{Feasibility of Hybrid Energy Aware Routing for Ad-hoc Network}

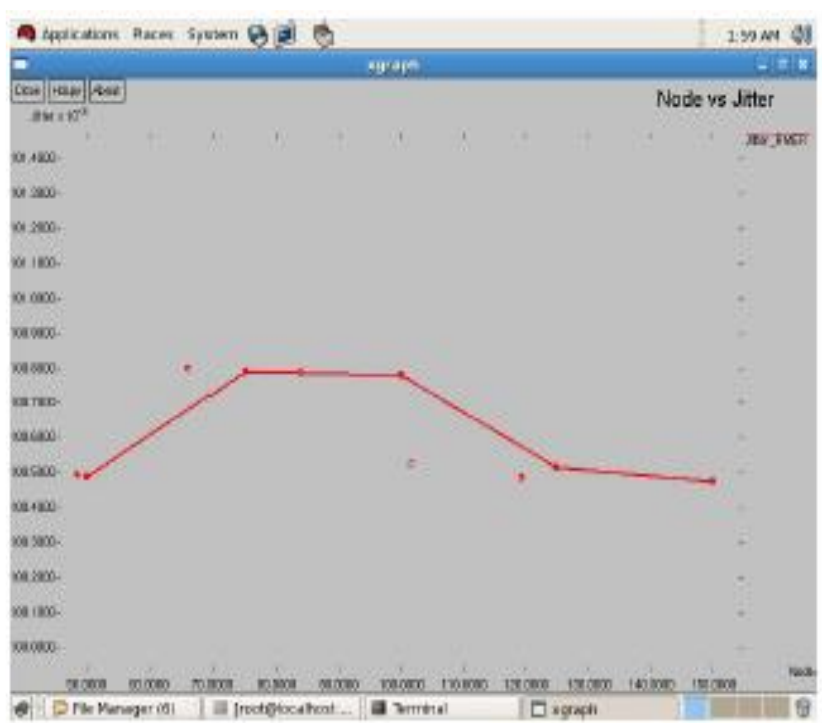

Figure 10 Node Vs Jitter

5. As per the Bata Krishna Tripathy, Ashray Sudhir, Padmalochan Bera, they proposed a formal framework for modelling and verification of constraints required and can be utilised in designing an adaptive routing protocols for MANET. In addition to the framework they have given emphasis on the Quality of Service (QoS) constraints. Which is proposed with few experimental results.

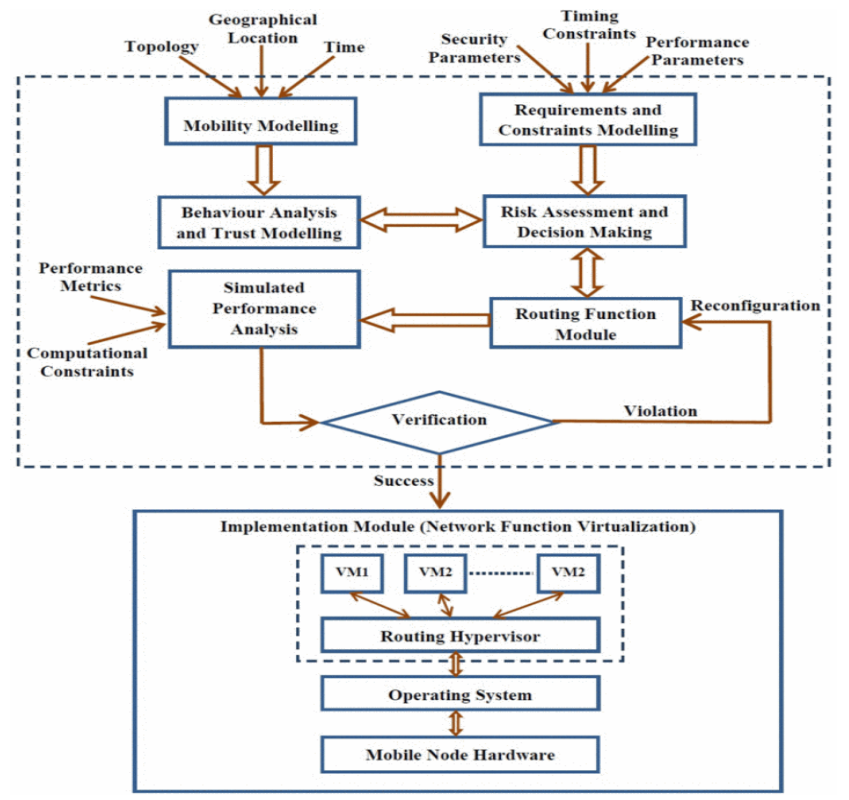

Figure 11.Adaptive Routing Design Framework

\section{IMPLEMENTATION}

\section{A. Overview}

The steps of the proposed method are as described in the algorithm given below. Here the algorithm is explained as given below.

\section{B. Proposed Methodology}

The entire methodology is explained in the algorithm given below.

\section{Algorithm:}

1. Search the nodes in close vicinity to the Source Node.

2. Source node finds the nodes in close vicinity and

3. The node which has maximum residual battery energy will be chosen and kept in the stack

4. The nodes which has minimum distances from the source node will be chosen and kept in the stack

5. The common node which has minimum distance and maximum residual battery energy will be considered as next node to form the network

6. This continues till we reach the destination node or the sink node where the data pocket needs to be transferred.

Performance is analysed based on the values of the parameters taken here.

Time taken to establish the network is calculated.

Efficiency is also calculated.

Energy Consumption is measured.

Delivery Ratio is compared

Graphical representation of tabular information is explained in detail.

Such network can survive for longer duration once we simulate it.

The results of the simulation are explained further with several parameters and their respective values.

\section{Statistics of Results}

Table 1.1 Comaprison Delay values in DSDV and AODV

\begin{tabular}{|c|c|c|c|c|c|}
\hline QoS & \multicolumn{5}{|c|}{ Delay } \\
\hline $\begin{array}{c}\text { Simulation } \\
\text { Pause } \\
\text { Time }\end{array}$ & 7.02 & 12.03 & 17.05 & 22.06 & 23 \\
\hline $\begin{array}{c}\text { DSDV- } \\
\text { ELFN }\end{array}$ & 1.5056 & 1.5923 & 1.6431 & 1.6789 & 1.7889 \\
\hline $\begin{array}{c}\text { AODV- } \\
\text { ELFN }\end{array}$ & 1.4545 & 1.4856 & 1.5267 & 1.6478 & 1.7889 \\
\hline
\end{tabular}




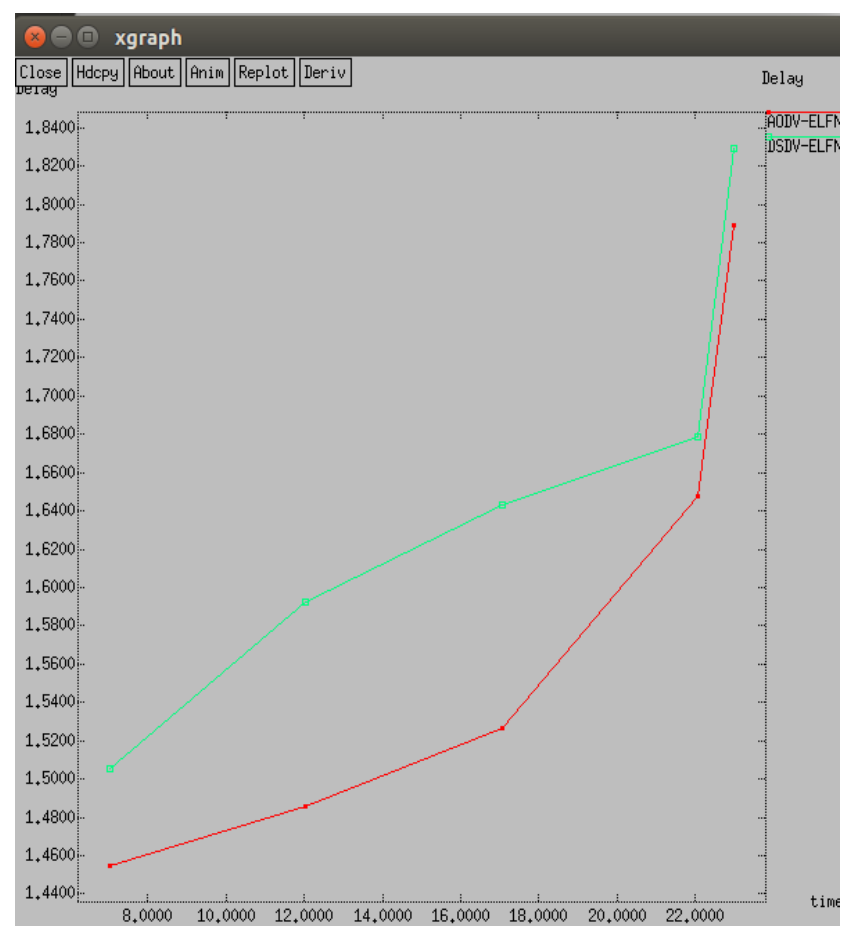

Figure12. Graph of Time Vs Delay w.r.t. Table 1.1

Table 1.2 Delivery Ratio of DSDV and AODV

\begin{tabular}{|c|c|c|c|c|c|}
\hline QoS & \multicolumn{5}{|c|}{ Delivery Ratio (Rate Value) } \\
\hline $\begin{array}{c}\text { Simulation } \\
\text { Time }\end{array}$ & 7.02 & 12.03 & 17.05 & 22.06 & 23.00 \\
\hline $\begin{array}{c}\text { DSDV- } \\
\text { ELFN }\end{array}$ & 33.723 & 33.776 & 33.800 & 33.865 & 33.890 \\
\hline $\begin{array}{c}\text { AODV- } \\
\text { ELFN }\end{array}$ & 33.768 & 33.794 & 33.818 & 33.870 & 33.913 \\
\hline
\end{tabular}

Table 1.3 Delivery Ratio for 500 Packets

\begin{tabular}{|c|c|c|c|c|c|}
\hline QoS & \multicolumn{5}{|c|}{ Delivery Ratio (Rate value/packet sent (500 Pkts) } \\
$* 100$ \\
\hline $\begin{array}{c}\text { Simulation } \\
\text { Time }\end{array}$ & 7.02 & 12.03 & 17.05 & 22.06 & 23.00 \\
\hline $\begin{array}{c}\text { DSDV- } \\
\text { ELFN }\end{array}$ & 6.7446 & 6.7552 & 6.76 & 6.773 & 6.778 \\
\hline $\begin{array}{c}\text { AODV- } \\
\text { ELFN }\end{array}$ & 6.7536 & 6.7588 & 6.7636 & 6.774 & 6.782 \\
\hline
\end{tabular}

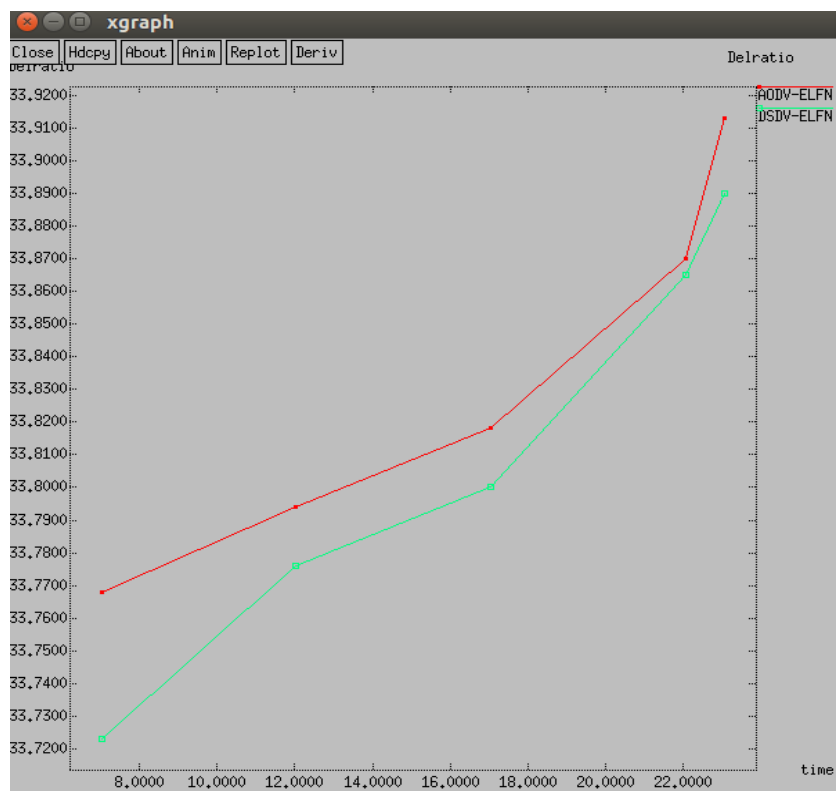

Figure 13. Graph of Time Vs Delay w.r.t. Table 1.2 and 1.3

Table 1.4 Energy Consumption

\begin{tabular}{|c|c|c|c|c|c|}
\hline QoS & \multicolumn{5}{|c|}{ Energy Consumption } \\
\hline $\begin{array}{c}\text { Simulation } \\
\text { Time }\end{array}$ & 20 & 40 & 60 & 80 & 10 \\
\hline $\begin{array}{c}\text { DSDV- } \\
\text { ELFN }\end{array}$ & 23.1456 & 25.1534 & 26.1634 & 27.1723 & 28.1834 \\
\hline $\begin{array}{c}\text { AODV- } \\
\text { ELFN }\end{array}$ & 23.1325 & 24.1486 & 26.1512 & 27.1678 & 28.1789 \\
\hline
\end{tabular}

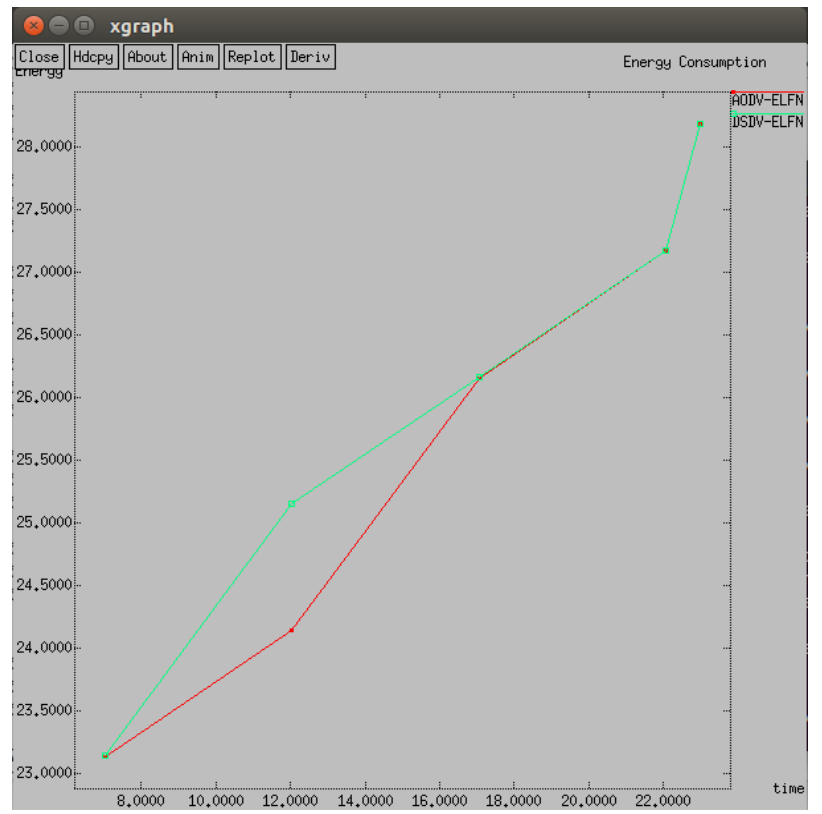

Figure 14. Time Vs Energy Consumption

The analysis of the above given DSDV ELFN and AODV ELFN is described here with several parametric values with its diagramatic representation which clearly pretends that, the overall dealy in time is caused in DSDV ELFN is less to thath of AODV ELFN and hence the Delivery Ratio is also efficient in DSDV ELFN over the AODV ELFN.

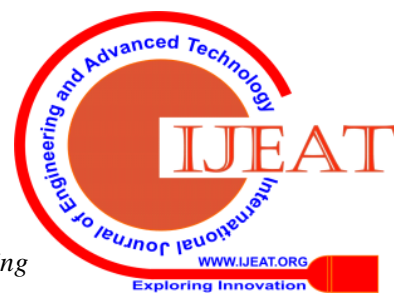




\section{Feasibility of Hybrid Energy Aware Routing for Ad-hoc Network}

The analysis is done for the 500 packets sent for the delivery ratio in terms of Rate Value / Packet sent is taken here for in detail analysis, where by the complete analysis with these three tables concludes that the overall efficiency in DSDV over the AODV is much better and this is what is utilised in the existing system where we have found the energy aware concept is dirrectly used with the distance based routing approach.

Quality of Service (QoS) has been given more emphasis for the judgement of the efficiency of the proposed hybridization.

Eventually this paves the way to reach to recapitulate that the overall efficiency and time requirement fo rhte establishment of the network will b easier to that of earlier existing system.and hence this helps us to forcast pragmatically that this seems to be an innovative approch which can be further implemented to avoid the call drop.

\section{CONCLUSION}

The reading and diagrammatic representation clears that, the proposed method is more efficient and can survive for more duration and consumes less energy, which in turn takes less time to transmit the message and avoids failure so again the energy is saved which we might have required to establish the network for the same work.

To conclude we can say the proposed method is most durable for message transmission for the given mobile ad hoc network even in network congestion. Since it chooses the node with which is found to be free.

\section{REFERENCES}

1. Londhe G.V., Hiren D. (2020) Hybrid Energy-Aware Routing (HEAR) Approach (Using Network Simulator. "Springer Singapore".online ISSN 978-981-15-0028-2,

2. Londhe G.V. An Energy Aware Routing Protocol with Sleep Scheduling for WSN International Journal of Science and Research (IJSR), India Online ISSN: 2319-7064

3. Indrajeet Banerjee, Suriti Chakrabarty, Arunava Bhattacharya, Utsav Ganguly "An Energy Aware Routing Design to Maximize Lifetime of a Wireless Sensor Network with a Mobile Base Station”.IEEE Conference 2014, ISSN 978-1-4799-3080-7/14

4. Magnus Eriksson anf Arif Mahmud, "Dynamic Single Frequency Networks in

5. Wireless Multihop Networks" IEEE Conference on Computer and Inforamtion Technology (CIT2010) .ISSN 978-0-7695-4108-2/10

6. Abdullah Konak,"A Distributed Multi-Agent Algorithm for Topology Control in Mobile Ad -hoc Networks" IEEE conference on Advanced Robotics (ICAR) Hong Kong, China, July 2017 ISSN 978-1-5386-3157-7/17

7. Priyanka R. More, Swati V. Sankpal,'Energy Aware Routing using Energy Efficient Routing Protocol in Wireless Ad hoc Network." IEEE Conference on Electrical And Electronoics, and Optimization Techniques (ICEEOT) 2016, ISSN 978-1-4673-9939-5/1/16

8. Bata Krishna Tripathy, Ashray Sudhir, Padmalochan Bera, Mohammad Ashiqur Rahman,'Formal Modelling and Verification of Requirements of Adaptive Routing Protocol for Mobile Ad-hoc Network" IEEE 41 ${ }^{\text {st }}$ Annual Computer Software and Applications Conference. ISSN 0730-3157/17

\section{AUTHORS PROFILE}

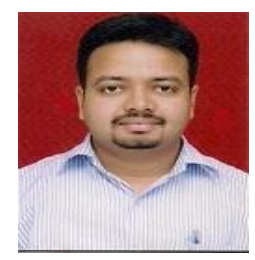

Mr. Gaurav Vishnu Londhe, Research Scholar of Department of Computer Science and Engineering, Pacific Academy of Higher Education and Research University Udaipur, Rajasthan, India. Currently associated with SVKM's Narsee Monjee Institute of Management Studies Deemed to be University as a Faculty of Department of Computer Engineering under the Mukesh Patel School of Technology Management and Engineering, Mumbai.Post Completion of Masters in Computer Engineering from University of Mumbai in an Energy aware routing for wireless ad hoc sensor networks. I was working with Datta Meghe College of Engineering as a Lecturer. Later joined NHITM New Horizon Institute of Technology and Management as an Assistant Professor in Department of Computer Engineering. Later Joined NMIMS University as an Assistant Registrar and now pursuing doctorate from Pacific Academy of Higher Education and Research University, Udaipur Rajasthan.

Dr. Dilendra Hiren, Faculty of Computer Science and Engineering, Pacific Academy of Higher Education and Research University, Udaipur, Rajasthan, India. 